\title{
Expression of a Class 1 Hemoglobin Gene and Production of Nitric Oxide in Response to Symbiotic and Pathogenic Bacteria in Lotus japonicus
}

\author{
Maki Nagata, ${ }^{1}$ Ei-ichi Murakami, ${ }^{1}$ Yoshikazu Shimoda, ${ }^{2}$ Fuyuko Shimoda-Sasakura, ${ }^{3}$ Ken-ichi Kucho, ${ }^{4}$ \\ Akihiro Suzuki, ${ }^{5}$ Mikiko Abe,${ }^{4}$ Shiro Higashi, ${ }^{4}$ and Toshiki Uchiumi ${ }^{4}$ \\ ${ }^{1}$ Graduate School of Science and Technology, Kagoshima University, Kagoshima 890-0065, Japan; ${ }^{2}$ National Institute \\ of Agrobiological Sciences, Tsukuba, Ibaraki 305-8602, Japan; ${ }^{3}$ Frontier Science Research Center and ${ }^{4}$ Department \\ of Chemistry and Bioscience, Faculty of Science, Kagoshima University, Kagoshima 890-0065, Japan; ${ }^{5}$ Department \\ of Agricultural Sciences, Faculty of Agriculture, Saga University, Saga 840-8502, Japan
}

Submitted 25 May 2008. Accepted 4 June 2008.

Symbiotic nitrogen fixation by the collaboration between leguminous plants and rhizobia is an important system in the global nitrogen cycle, and some molecular aspects during the early stage of host-symbiont recognition have been revealed. To understand the responses of a host plant against various bacteria, we examined expression of hemoglobin (Hb) genes and production of nitric oxide (NO) in Lotus japonicus after inoculation with rhizobia or plant pathogens. When the symbiotic rhizobium Mesorhizobium loti was inoculated, expression of $\mathrm{LjHbl}$ and NO production were induced transiently in the roots at $4 \mathrm{~h}$ after inoculation. In contrast, inoculation with the nonsymbiotic rhizobia Sinorhizobium meliloti and Bradyrhizobium japonicum induced neither expression of $\mathrm{LjHb1}$ nor NO production. When L. japonicus was inoculated with plant pathogens (Ralstonia solanacearum or Pseudomonas syringae), continuous NO production was observed in roots but induction of $\mathrm{LjHb1}$ did not occur. These results suggest that modulation of NO levels and expression of class $1 \mathrm{Hb}$ are involved in the establishment of the symbiosis.

Leguminous plants form root nodules, in which symbiotic rhizobia fix atmospheric nitrogen and supply the fixation products to their host plants as a nitrogen source. The nodulation process of legume-rhizobium symbiosis consists of a series of events initiated by an exchange of specific signaling compounds between both partners.

Plant hemoglobin $(\mathrm{Hb})$ was first reported as leghemoglobin (Lb) in the root nodules of Glycine max (Kubo 1939). Since their discovery, $\mathrm{Hb}$ have been identified in both leguminous and nonleguminous plants, and $\mathrm{Hb}$ are now believed to exist in all plants (Arredondo-Peter et al. 1998; Hill 1998). There are at least three distinct types of plant $\mathrm{Hb}$ : class 1 , class 2 , and truncated (Dordas et al. 2003a). All Lb belong to class 2. Lb of legumes and a class $2 \mathrm{Hb}$ of Casuarina glauca, which establishes symbiosis with nitrogen-fixing Frankia bacteria, function as both an oxygen transporter to allow respiration of microsymbionts in the nodules and an oxygen regulator to keep a

Corresponding author: T. Uchiumi; E-mail: uttan@ @sci.kagoshima-u.ac.jp; Telephone: +81-99-285-8164; Fax: +81-99-285-8163

* The $e$-Xtra logo stands for "electronic extra" and indicates that two supplementary figures are published online. low oxygen concentration for nitrogenase activity of nitrogenfixing bacteria in the symbiotic zone (Appleby 1992).

Although class $1 \mathrm{Hb}$ have been identified in many plant species (Hunt et al. 2001), their functions are not fully understood. Class $1 \mathrm{Hb}$ exhibit an extremely high affinity for oxygen (Arrendondo-Peter et al. 1997; Trevaskis et al. 1997) and nitric oxide (NO) (Dordas et al. 2004; Perazzolli et al. 2004). In plants, NO is produced under various conditions and serves as a signal molecule that induces the plant defense system (Dordas et al. 2003b; Durner et al. 1998). Dordas and associates (2004) reported that NO was produced in maize cell-suspension cultures by nitrate reductase during hypoxia, and class $1 \mathrm{Hb}$ had a significant function in regulating NO levels. In another study, transgenic alfalfa-root cultures overexpressing barley $\mathrm{Hb}$ showed lower levels of NO and a lower rate of cell disruption as compared with wild-type root under hypoxia (Dordas et al. 2003b). A class $1 \mathrm{Hb}$ gene of Arabidopsis thaliana, $A H B 1$, is strongly induced by hypoxia, sucrose treatment (Trevaskis et al. 1997), and nitrate addition (Wang et al. 2000). A transgenic line of A. thaliana overexpressing AHB1 showed an increased survival rate under severe hypoxic conditions (Hunt et al. 2002). The overexpression of $\mathrm{GhHbl}$, a class $1 \mathrm{Hb}$ gene of cotton, in Arabidopsis increased disease tolerance $(\mathrm{Qu}$ et al. 2006). These reports indicate that class $1 \mathrm{Hb}$ control various NO-regulated physiological processes of plants by modulating NO levels (Seregélyes et al. 2003, 2004).

In many plants, infection by pathogens was shown to induce the expression of pathogenesis-related genes, including the phenylalanine ammonia-lyase (PAL) and chalcone synthase (CHS) genes (Mishina and Zeier 2007; Zabala et al. 2006). PAL and CHS are involved in the phenylpropanoid metabolic pathway leading to the synthesis of phytoalexins and other phenolic compounds in response to pathogen attack. When G. max was inoculated with the symbiotic rhizobia Bradyrhizobium japonicum, PAL and CHS were induced during the early stages of the interaction (Estabrook and Sengupta-Gopalan 1991). CHS of Trifolium subterraneum was induced with inoculation of Rhizobium leguminosarum bv. trifolii, but no induction of $C H S$ was detected in uninoculated plants and with inoculation of the heterologous rhizobia Sinorhizobium meliloti (Lawson et al. 1994). The early stages of the interaction between plants and symbiotic and pathogenic bacteria have much in common (Baron and Zambryski 1995); the reactions against symbiotic rhizobia resemble plant defense response to pathogens. However, it is 
unclear how rhizobia cancel the induction of the plant defense system to establish the symbiosis.

Two class $1 \mathrm{Hb}$ genes and three class $2 \mathrm{Hb}(\mathrm{Lb})$ genes exist in the genome of Lotus japonicus (Uchiumi et al. 2002). The Lb genes of $L$. japonicus $(L j L b)$ are expressed exclusively in root nodules. $L j H b 1$, one of the class $1 \mathrm{Hb}$ genes of $L$. japoni$c u s$, is strongly induced under both hypoxic and cold stresses, and the gene is induced as well by treatment with the NO donor $S$-nitroso- $N$-acetyl-D, L-penicillamine, and inoculation with the symbiotic rhizobium Mesorhizobium loti MAFF303099 (Shimoda et al. 2005). Although NO generation was induced by $M$. loti MAFF303099, the intensity was less than that under cold and hypoxia conditions. Observations using fluorescence microscopy revealed the induction of $\mathrm{LjHbl}$ expression corresponded to the generation of NO. These results suggest that $\mathrm{LjHb1}$ and NO have roles in stress adaptation and during the early stage of legume-rhizobium symbiosis (Shimoda et al. 2005).
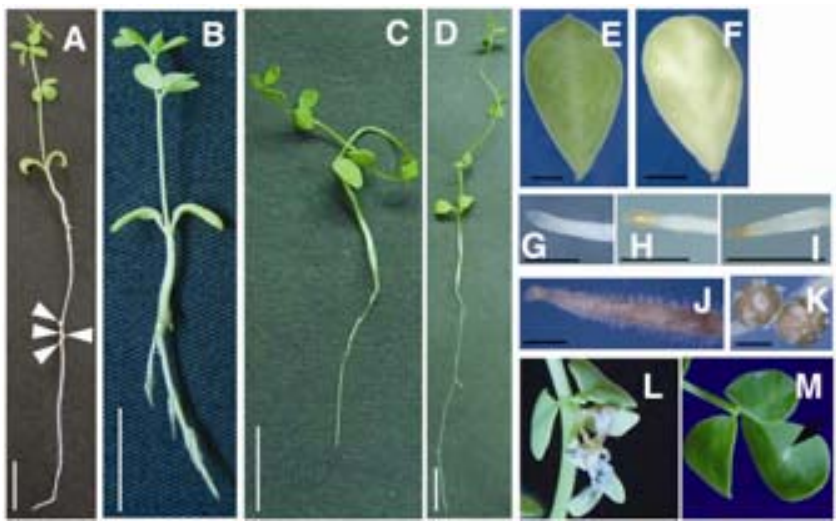

Fig. 1. Lotus japonicus inoculated with symbiotic rhizobia and plant pathogens. A through D, Whole Lotus japonicus plants, $\mathbf{E}$ and $\mathbf{F}$, leaves, and $\mathbf{G}$ through $\mathbf{J}$, root tips, and $\mathbf{K}$, nodules inoculated by symbiotic rhizobia and plant pathogens at 28 days after inoculation with Mesorhizobium loti MAFF303099 (A, E, G, and K), Ralsonia solanacearum (B, F, and J), Pseudomonas syringae pv. pisi MAFF730032 (C and $\mathrm{H})$, and $P$. syringae pv. glycinea MAFF302690 (D and I). L, Leaves at 5 days after infiltration with $R$. solanacearum MAFF730135 and M, with M. loti MAFF303099. White bars $=1 \mathrm{~cm}$ (A through D); black bars = $1 \mathrm{~mm}$ (E through $\mathrm{K})$. In A, arrowheads indicate nodules; in $\mathrm{M}$, the arrow indicates the site where $M$. loti MAFF303099 was injected.
To understand the responses of leguminous plants against microbes in the rhizosphere, including rhizobia and pathogens, in the present study, we investigated the expression of $\mathrm{LjHbl}$ and production of $\mathrm{NO}$ in L. japonicus. L. japonicus plants were inoculated with symbiotic or nonsymbiotic rhizobial strains or plant pathogens. The timecourse of the expression level of $\mathrm{LjHbl}$ was estimated by real-time reverse transcriptase-polymerase chain reaction (RT-PCR) at various time intervals up to $24 \mathrm{~h}$ after bacterial inoculation. NO production in L. japonicus was observed using the fluorescent dye 4-amino5-methylamino-2', $7^{\prime}$-difluorescein diacetate (DAF-FM DA) as a NO-specific detector. Our findings will improve understanding of the functions of class $1 \mathrm{Hb}$ and $\mathrm{NO}$ in the plant recognition system for symbiotic and pathogenic microbes.

\section{RESULTS}

Responses of $L$. japonicus induced by plant pathogens.

L. japonicus plants inoculated with the symbiotic rhizobium M. loti MAFF303099 grew well, with the formation of nitrogenfixing nodules (Fig. 1A and K). Their leaves were green (Fig. 1E) and no pigmentation was observed in the root tips (Fig. $1 G)$. In contrast, when L. japonicus was inoculated with the plant pathogen $R$. solanacearum MAFF730135, etiolation of leaves, brownish pigmentation of the elongation zone of the root tip, and inhibition of plant growth were observed by 28 days after inoculation (Fig. 1B, F, and J). Similarly, at 28 days after inoculation with the plant pathogen $P$. syringae pv. pisi MAFF730032, brownish pigmentation of the meristematic zone of the root tip, inhibition of primary root elongation, and curling of shoots were observed (Fig. 1C and H). When L. japonicus was inoculated with the plant pathogen $P$. syringae pv. glycinea MAFF302690, brownish pigmentation of the meristematic zone of the root tip was observed but shoots grew like those of uninoculated plants (Fig. 1D and I). It is known that infiltration of these plant pathogens induce characteristic responses on the leaf of $L$. japonicus (for $R$. solanacearum MAFF730135, H. Kaku and H. Ochiai, unpublished data; for P. syringae pvs. pisi MAFF730032 and glycinea MAFF302690, T. Nakagawa and K. Takeuchi, unpublished data). We performed infiltration experiments according to their findings. When $R$. solanacearum MAFF730135 was infiltrated into leaves of L. japonicus, the leaves wilted and dropped but the symptom was restricted to the infiltrated leaf (Fig. 1L). Infiltration of

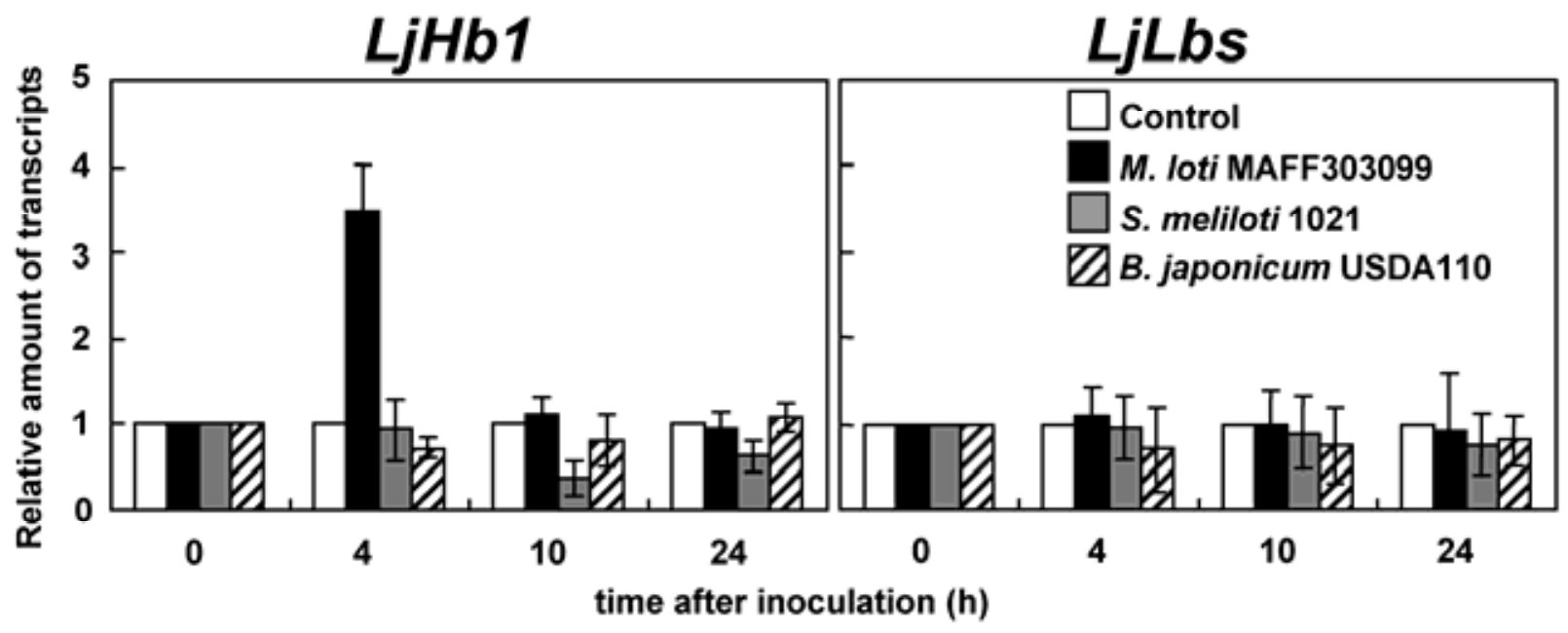

Fig. 2. Expression of hemoglobin genes in Lotus japonicus by inoculation with rhizobia. L. japonicus was inoculated with symbiotic rhizobium Mesorhizobium loti MAFF303099 (black bars), or nonsymbiotic rhizobia Sinorhizobium meliloti 1021 (gray bars) or Bradyrhizobium japonicum USDA110 (hatched bars). Control plants were treated with sterilized water (white bars). Total RNAs were isolated from whole plants at the indicated times after inoculation. Relative amounts of transcripts, as normalized against control plants, are shown. Data represent the average of three independent experiments with standard error. 
$P$. syringae pv. pisi MAFF730032 caused similar symptoms as those of $R$. solanacearum MAFF730135 (data not shown). Infiltration of $P$. syringae pv. glycinea MAFF302690 (data not shown) and M. loti MAFF303099 (Fig. 1M) caused no obvious disease symptoms. These results indicate that the characteristic responses observed by inoculation of roots or infiltration of leaves of L. japonicus depend on the plant pathogens.

\section{Expression of plant $\mathrm{Hb}$ genes}

in response to rhizobia and plant pathogens.

To examine the responses of $L j H b l$ and $L j L b$ to rhizobia, the roots of $L$. japonicus plants were inoculated with the symbiotic rhizobial strain $M$. loti MAFF303099 or the nonsymbiotic rhizobial strains $S$. meliloti 1021 or B. japonicum USDA110. Total RNA was prepared from a whole plant, and the expression levels of $L j H b l$ and $L j L b$ were estimated by quantitative RT-PCR.
Inoculation with $M$. loti MAFF303099 induced transient expression of $\mathrm{LjHbl}$; the expression of $\mathrm{LjHbl}$ increased at $4 \mathrm{~h}$ after inoculation and decreased to its basal level at $10 \mathrm{~h}$ (Fig. 2). At $4 \mathrm{~h}$ after inoculation, the expression level of $\mathrm{LjHbl}$ in plants inoculated with $M$. loti was enhanced approximately three times higher than that of control plants. However, inoculation with the nonsymbiotic rhizobia $S$. meliloti 1021 and $B$. japonicum USDA110 did not induce the expression of $\mathrm{LjHbl}$ (Fig. 2). $L j L b$ (the three class $2 \mathrm{Hb}$ genes of L. japonicus) did not respond to inoculation with rhizobial strains (Fig. 2).

To further investigate how the induction of class $1 \mathrm{Hb}$ genes by symbiotic rhizobia generally occurs in leguminous plants, the expression of Mhbl (class $1 \mathrm{Hb}$ of Medicago sativa) and $M s L b$ (Lb of Medicago sativa) were also analyzed. When roots of Medicago sativa were inoculated with the symbiotic rhizobium S. meliloti 1021, the expression of Mhbl was enhanced transiently, similar to the case of $L$. japonicus with $M$. loti

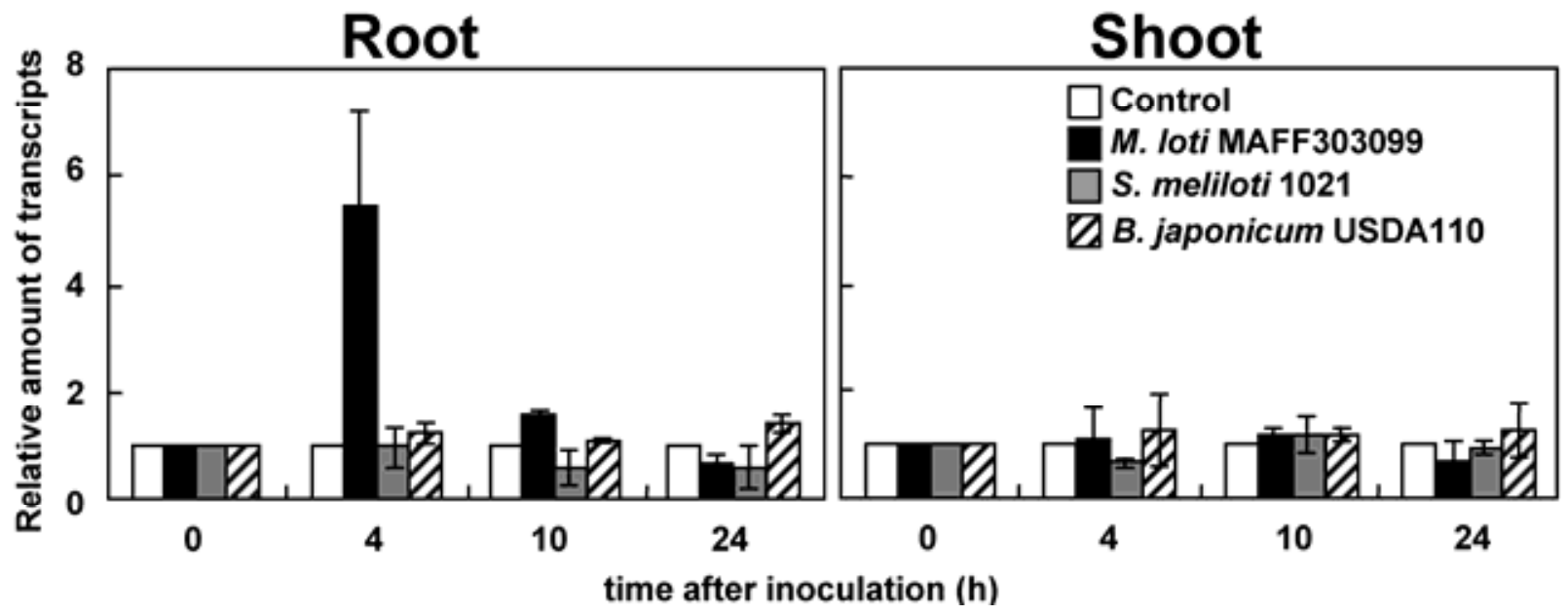

Fig. 3. Expression of the Lotus japonicus Hbl gene in roots and shoots. L. japonicus plants were inoculated with Mesorhizobium loti MAFF303099 (black bars), Sinorhizobium meliloti 1021 (gray bars), or Bradyrhizobium japonicum USDA110 (hatched bars). Control plants were treated with sterilized water (white bars). Total RNAs were isolated from roots and shoots at the indicated times after inoculation. Relative amounts of transcripts normalized by control plants are shown. Data represent the average of three independent experiments with standard error

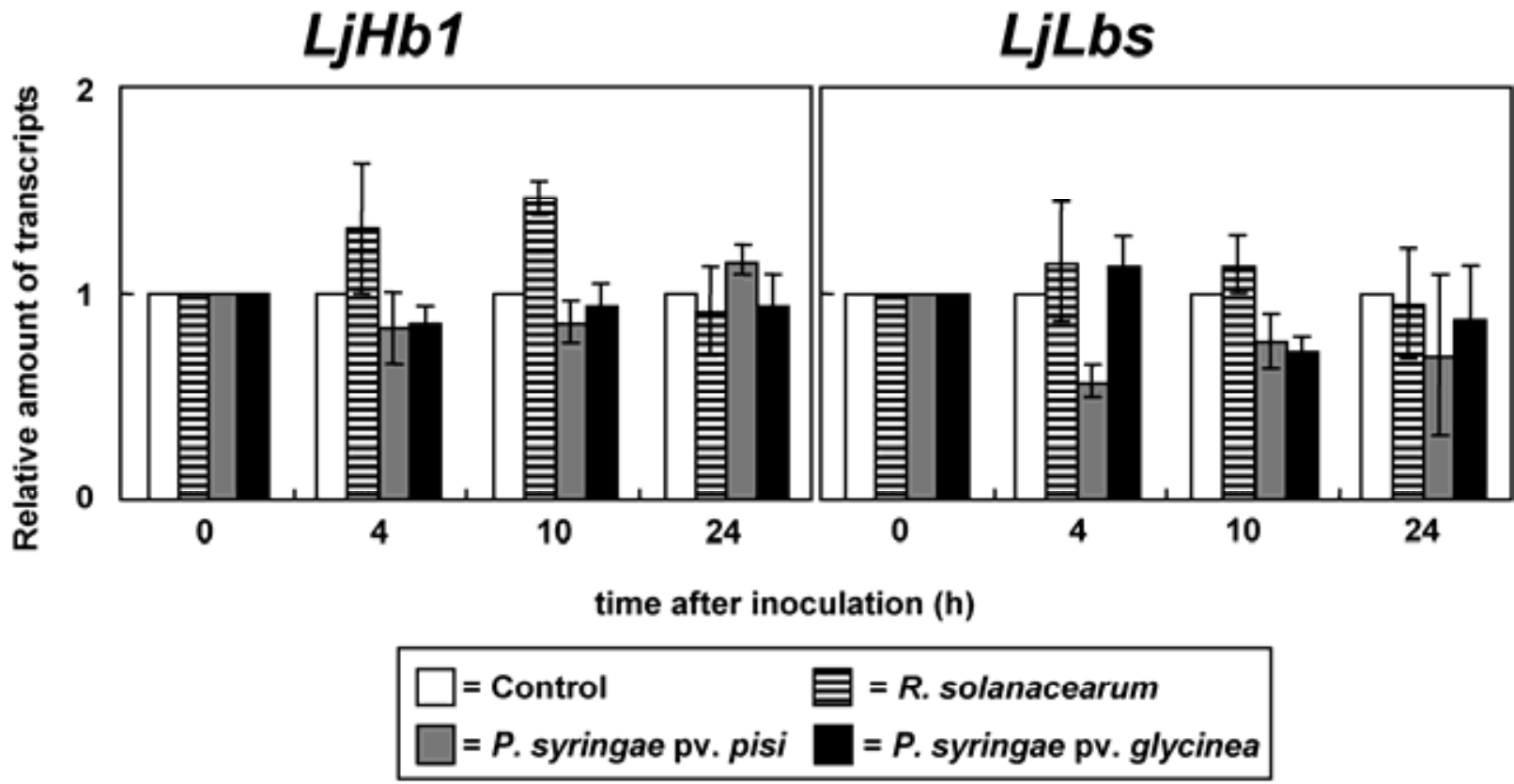

Fig. 4. Expression of hemoglobin genes by inoculation with plant pathogens. Lotus japonicus was inoculated with Ralstonia solanacearum (hatched bars), Pseudomonas syringae pv. pisi (gray bars), or P. syringae pv. glycinea (black bars). Control plants were treated with sterilized water (white bars). Relative amounts of transcripts, as normalized against control plants, are shown. Time indicates the sampling time after inoculation with plant pathogens. Data represent the average of three independent experiments with standard error. 
MAFF303099. The expression of $M h b l$ increased at $4 \mathrm{~h}$ after inoculation and decreased to the basal levels at $10 \mathrm{~h}$. The expression level of $M s L b$ in infected plants did not change (Supplementary Fig. 1). The inoculation with the nonsymbiotic rhizobium $M$. loti MAFF303099 induced neither Mhbl nor $M s L b$ (data not shown). These data clearly indicate that only symbiotic rhizobia induce transient expression of class $1 \mathrm{Hb}$ genes in their host legumes.

The location of $\mathrm{LjHbl}$ expression was examined by quantitative RT-PCR. When M. loti MAFF303099 was inoculated, the expression of $\mathrm{LjHbl}$ was enhanced in roots to about five times the level of uninfected root at $4 \mathrm{~h}$ after inoculation (Fig. 3 ), whereas $\mathrm{LjHbl}$ was expressed at basal levels in the shoot. In the case of inoculation with S. meliloti 1021 or B. japonicum USDA110, the expression level of $\mathrm{LjHbl}$ did not change either in shoot or root (Fig. 3). These results indicate that the expression of $\mathrm{LjHbl}$ was enhanced transiently only in the roots by inoculation with symbiotic rhizobia.

The responses of $L j H b l$ and $L j L b$ to the plant pathogens were also examined. When roots of L. japonicus were inocu-

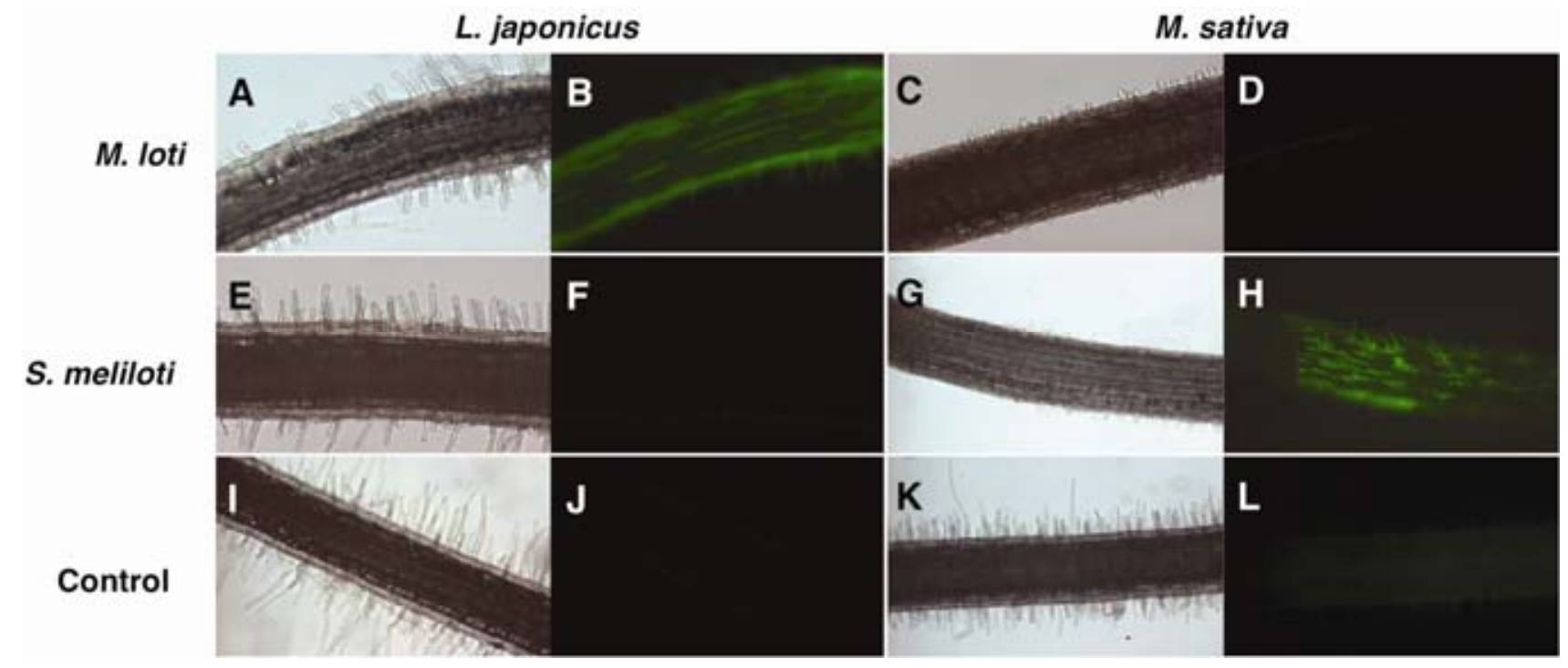

Fig. 5. Nitric oxide (NO) production by inoculation with symbiotic and nonsymbiotic rhizobia. A through D, Mesorhizobium loti MAFF303099 and E through $\mathbf{H}$, Sinorhizobium meliloti 1021 were used to inoculate Lotus japonicus (A, B, E, F, I, and J) and Medicago sativa (C, D, G, H, K, and L). I through $\mathbf{L}$, As a control, sterilized distilled water was applied instead of rhizobia. Images of roots were taken at $4 \mathrm{~h}$ after inoculation by fluorescence microscopy, using 4-amino-5-methylamino-2',7'-difluorescein diacetate as a NO detector (B, D, F, H, J, and L) and Bright-field imaging (A, C, E, G, I, and K).

\section{L. japonicus + M. loti}

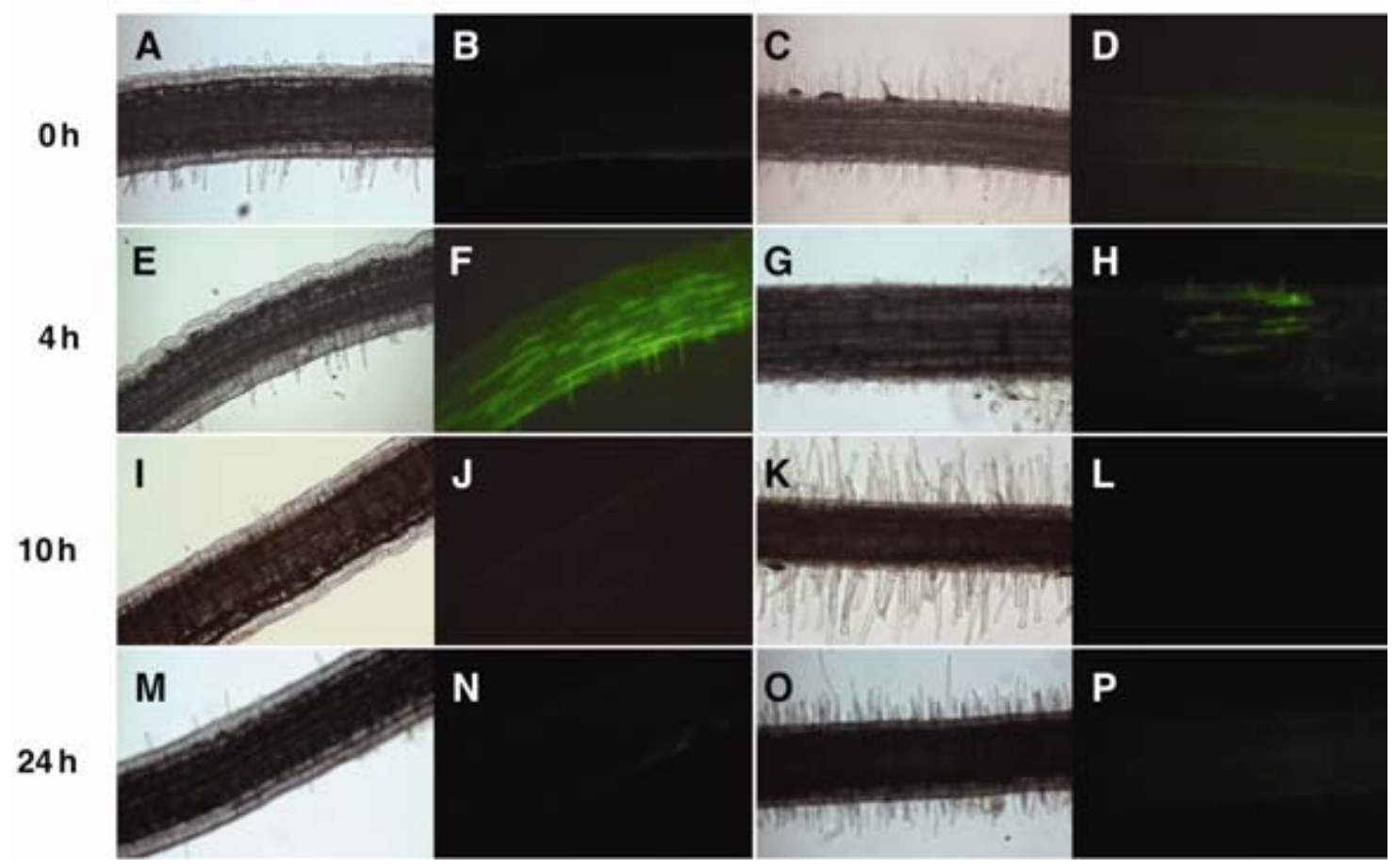

Fig. 6. Nitric oxide (NO) production at various times after rhizobial inoculation. Roots of Lotus japonicus and Medicago sativa at $\mathbf{A}$ through $\mathbf{D}, 0 \mathrm{~h}, \mathbf{E}$ through $\mathbf{H}$, $4 \mathrm{~h}$, I through $\mathbf{L}, 10 \mathrm{~h}$, and M through P, $24 \mathrm{~h}$ after inoculation with Mesorhizobium loti MAFF303099 (A, B, E, F, I, J, M, and N) and Sinorhizobium meliloti 1021 (C, D, G, H, K, L, O, and P). NO production was observed by fluorescence microscopy, using 4-amino-5-methylamino-2',7'-difluorescein diacetate (B, D, F, H, J, L, N, P), and Bright-field imaging (A, C, E, G, I, K, M, and O). 
lated with $R$. solanacearum MAFF730135, $P$. syringae pv. pisi MAFF730032, or P. syringae pv. glycinea MAFF302690, expression of neither $L j H b 1$ nor $L j L b$ was induced (Fig. 4).

\section{NO production by inoculation} with rhizobia and plant pathogens.

In accordance with the expression of $\mathrm{LjHbl}$, NO was detected in the roots of $L$. japonicus by $4 \mathrm{~h}$ after $M$. loti inoculation (Shimoda et al. 2005). To assess the specificity of NO production, cross-inoculation tests were performed, and the roots were observed using the dye DAF-FM DA as a NOspecific detector.

The distinct fluorescence was detected when the roots of $L$. japonicus (Fig. 5A and B), Medicago sativa (Fig. 5G and $\mathrm{H}$ ), and Trifolium repens (Supplementary Fig. 2) were inoculated with their symbiotic rhizobia $M$. loti MAFF303099, S. meliloti 1021, and Rhizobium leguminosarum bv. trifolii 4S, respectively. In contrast, the fluorescence was not observed when those plants were inoculated with nonsymbiotic rhizobia (Fig. $5 \mathrm{C}$ through $\mathrm{F}$ ). The distinct fluorescence as a response to symbiotic rhizobia was transiently observed at $4 \mathrm{~h}$ after inoculation (Fig. 6E through $\mathrm{H}$ ) and, then, the intensity decreased to its basal level at $10 \mathrm{~h}$ (Fig. 6I through L). These results suggest that symbiotic rhizobia specifically induce transient NO production in the roots of its host plant in a pattern similar to that of $\mathrm{LjHbl}$ expression.

When $L$. japonicus was inoculated with $R$. solanacearum MAFF730135, P. syringae pv. pisi MAFF730032, or P. syringae pv. glycinea MAFF302690, strong fluorescence was detected at $4 \mathrm{~h}$ after inoculation (Fig. 7A through F). Furthermore, the fluorescence was detectable until at least $24 \mathrm{~h}$ after inoculation (Fig. 7G through R). These observation suggests that the plant pathogens induce continuous NO production in the root of L. japonicus.

\section{Effect of NO scavenger on the induction of $\mathrm{LjHb1}$.}

To make clear whether the induction of $\mathrm{LjHbl}$ is mediated by $\mathrm{NO}$, the expression of $\mathrm{LjHbl}$ and NO production was examined, using L. japonicus plants inoculated by M. loti MAFF303099 with or without a NO scavenger, carboxy-2-pheny1-4,4,5,5tetramethylimidazoline-3-oxide-1-oxyl (c-PTIO). At $3 \mathrm{~h}$ after inoculation, the plants were placed for $1 \mathrm{~h}$ on filter paper soaked with $1 \mathrm{mM}$ c-PTIO and the expression of $\mathrm{LjHbl}$ was determined by quantitative RT-PCR. In inoculated plants treated with c-PTIO, the expression of $\mathrm{LjHbl}$ was strongly repressed (Fig. 8A). The roots were observed by fluorescent microscope using DAF-FM DA. The fluorescence intensity of roots treated with c-PTIO was very low compared with that of roots without c-PTIO (Fig. 8B). The very deep color of cPTIO solution sometimes masks the green fluorescence. However, c-PTIO did not mask the fluorescence of roots expressing the green fluorescent protein gene when we observed by the method used in this study. Considering the results of the other combination of host-microsymbiont (Fig. 5), these results suggest that the inoculation of rhizobia induces NO production and expression of class $1 \mathrm{Hb}$ genes of host plants.

\section{Quantification of NO produced by bacterial inoculation.}

NO production in the roots inoculated with bacteria was detected by the fluorescent dye DAF-FM, and relative fluorescent unit (RFU) values were estimated. When L. japonicus was inoculated with $M$. loti MAFF303099, the RFU value increased

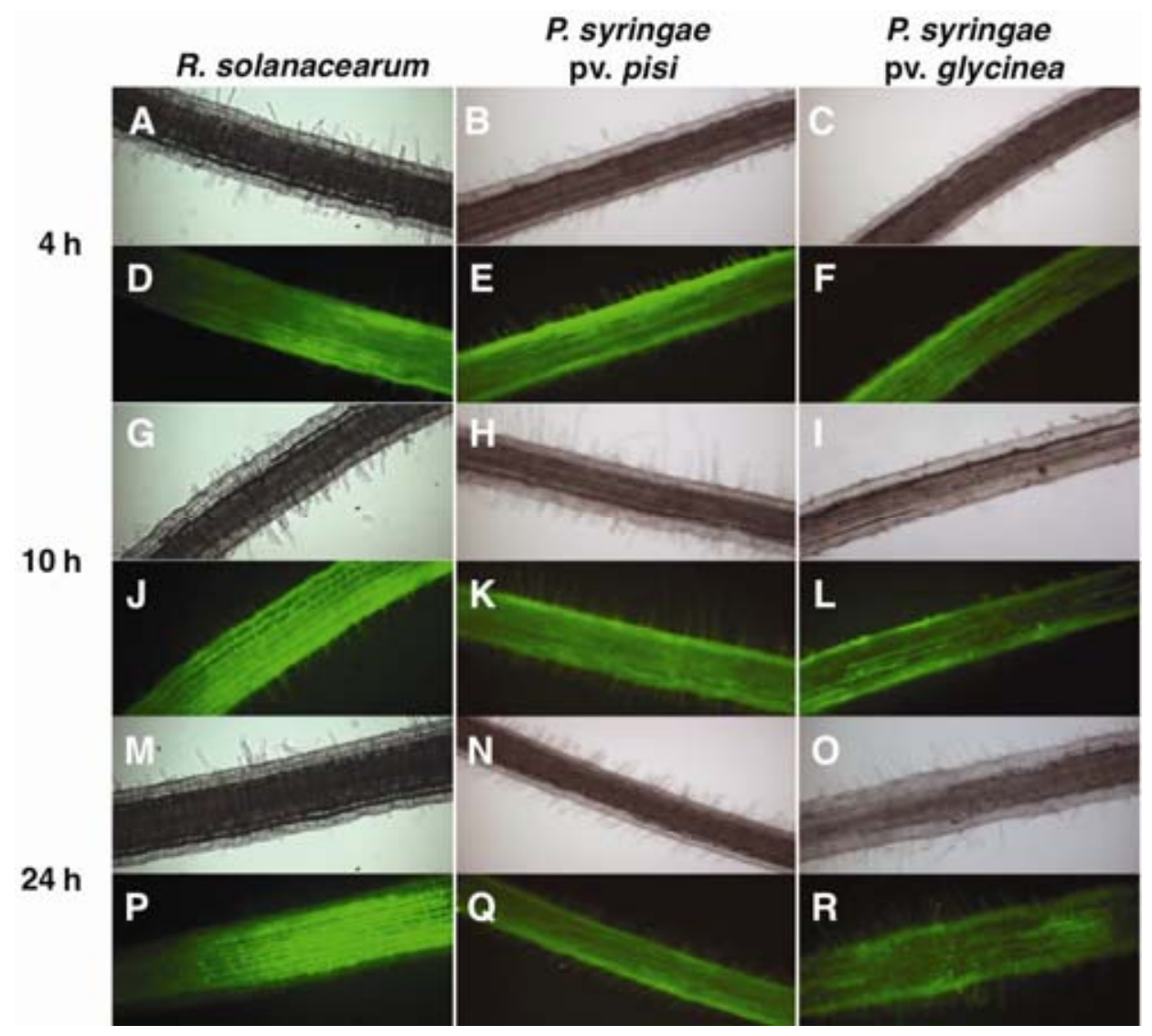

Fig. 7. Nitric oxide (NO) production by inoculation with plant pathogens. Roots of Lotus japonicus at $\mathbf{A}$ through $\mathbf{F}, 4 \mathrm{~h}, \mathbf{G}$ through $\mathbf{L}, 10 \mathrm{~h}$, and $\mathbf{M}$ through R, $24 \mathrm{~h}$ after inoculation with Ralstonia solanacearum (A, D, G, J, M, and P), Pseudomonas syringae pv. pisi (B, E, H, K, N, and Q), or P. syringae pv. glycinea (C, F, I, L, O, and R). NO production was observed by fluorescence microscopy, using 4-amino-5-methylamino-2',7'-difluorescein diacetate (D through F, J through L, and P through R) and Bright-field imaging (A through C, G through I, and M through O). 
at $4 \mathrm{~h}$ after inoculation and decreased to the basal level at $10 \mathrm{~h}$ (Fig. 9). In contrast, inoculation with $R$. solanacearum MAFF730135 induced continuous NO production until at least $24 \mathrm{~h}$ after inoculation (Fig. 9). Likewise, inoculation with $P$. syringae pv. pisi MAFF730032 and $P$. syringae pv. glycinea MAFF302690 also induced continuous NO production (Fig. 9).

\section{DISCUSSION}

We analyzed the responses of $L$. japonicus against the plant pathogens $R$. solanacearum and $P$. syringae pvs. pisi and glycinea. The effects of these bacterial strains will be helpful in understanding the responses of the model legume L. japonicus against various microorganisms. $R$. solanacearum is the causal agent of bacterial wilt and attacks more than 200 plant species, including legumes. $R$. solanacearum GMI1000 induces typical symptoms on Medicago truncatula A17, namely, chlorosis on cotyledons and the first leaf, and inhibition of development of secondary roots and leaves (Vailleau et al. 2007). P. syringae causes disease symptoms ranging from leaf spots to stem cankers on many plant species (Nomura et al. 2005). P. syringae enters the host tissues (usually leaves) through wounds and natural openings, such as stomata, and the pathogen multiplies to high population numbers in the intercellular spaces (Katagiri et al. 2002). Although none of the plant pathogens we used (i.e., R. solanacearum MAFF730135, P. syringae pv. pisi MAFF730032, and $P$. syringae pv. glycinea MAFF302690) are pathogens of $L$. japonicus in nature, the characteristic responses were observed on L. japonicus after inoculation of roots or infiltration of leaves (Table 1).
In inoculated root tissues, NO was produced transiently against the symbiotic rhizobium $M$. loti but continuously against all plant pathogens we used (Figs. 6 and 7). In plants, $\mathrm{NO}$ is involved in root growth, leaf expansion, photomorpho-

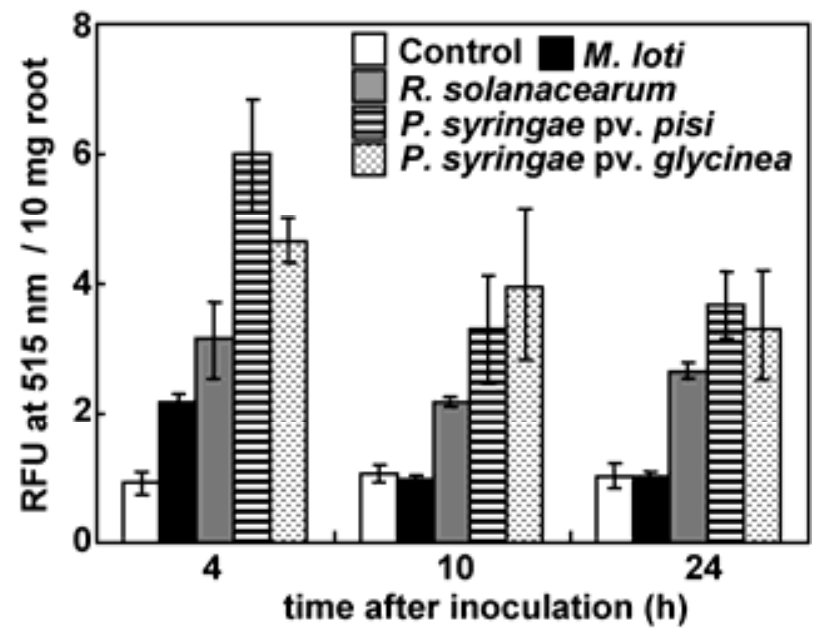

Fig. 9. Quantification of nitric oxide produced in roots. Roots of Lotus japonicus were inoculated with Mesorhizobium loti MAFF303099 (black bars), Ralstonia solanacearum MAFF730135 (gray bars), Pseudomonas syringae pv. pisi (hatched bars), and P. syringae pv. glycinea (dotted bars). Roots of L. japonicus treated with sterilized water were used as control (white bars). Relative fluorescent units (RFU) per $10 \mathrm{mg}$ of roots at 515 $\mathrm{nm}$ normalized against control plants are shown. The data represent the average of three independent experiments with standard error.
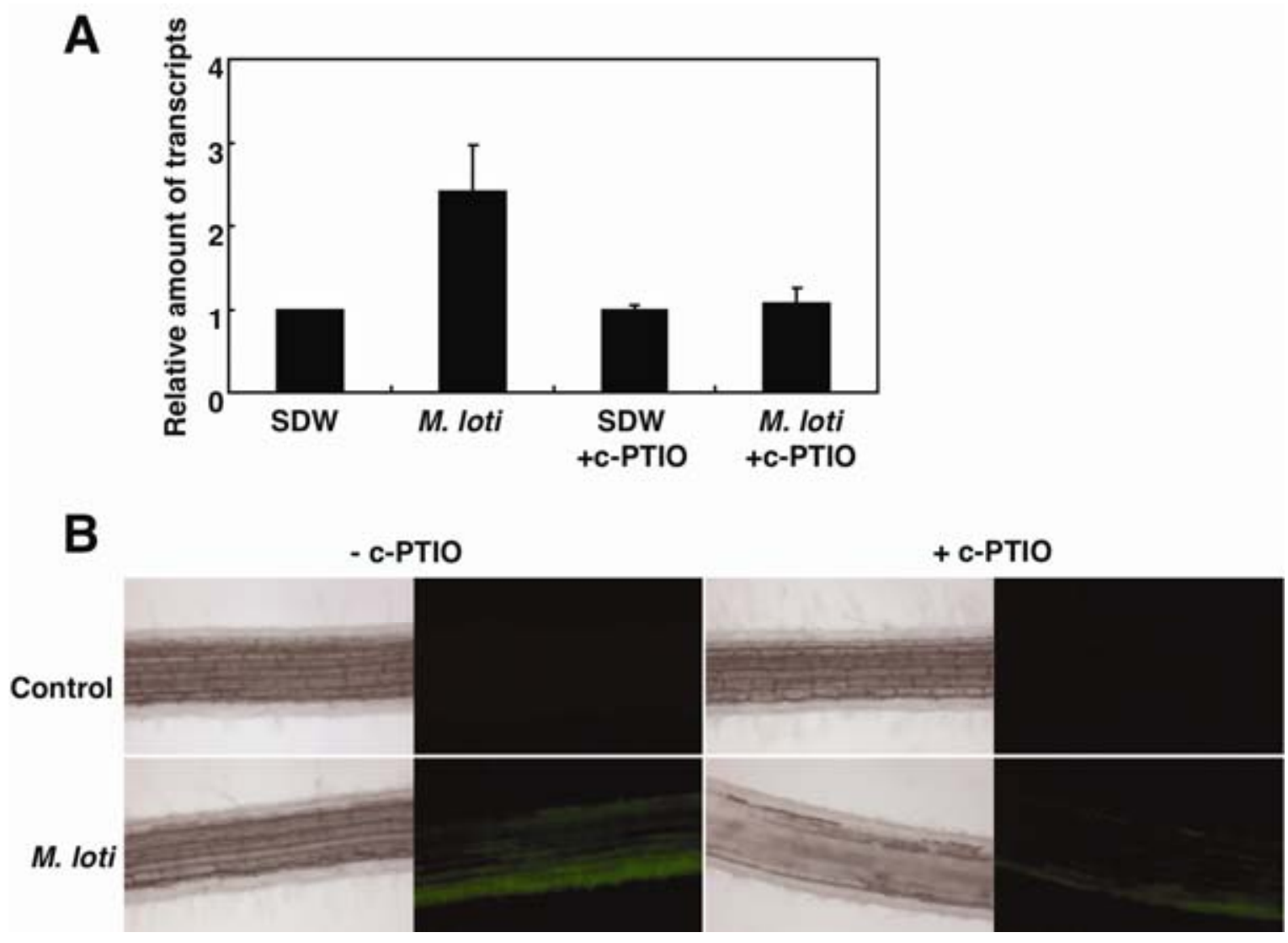

Fig. 8. Effect of nitric oxide (NO) scavenger on Lotus japonicus Hb1 (LjHbl) gene expression. A, The expression of LjHb1 was examined using Lotus japonicus plants inoculated with Mesorhizobium loti MAFF303099 with or without NO scavenger carboxy-2-pheny1-4,4,5,5-tetramethylimidazoline-3-oxide1-oxyl (c-PTIO) by quantitative reverse transcription-polymerase chain reaction. Control plants were treated with sterilized water (SDW). Relative amounts of transcripts normalized against control plants are shown. Data represent the average of three independent experiments with standard error. B, Detection of fluorescence, using 4-amino-5-methylamino-2',7'-difluorescein diacetate in roots treated with 1 mM c-PTIO. 
genesis senescence (Beligni and Lamattina 2000; Neill et al. 2003), and stomatal closure (Desikan et al. 2004). The production of $\mathrm{NO}$ and reactive oxygen species (ROS) is induced by pathogen attack (Hancock et al. 2002). NO is one of the key molecules in plant defense against pathogenic bacteria, and it induces the expression of defense genes and the accumulation of antimicrobial compounds such as phytoalexin (Delledonne 2005; Polverari et al. 2003; Romero-Puertas et al. 2004).

Various defense reactions might occur during the process of legume-rhizobium symbiotic interactions. For instance, Medicago sativa responds to infection with $S$. meliloti by the production of superoxide and hydrogen peroxide (Santos et al. 2001). Our previous study indicated that $M$. loti induces NO production in the roots of L. japonicus during the first hours of infection (Shimoda et al. 2005). Transcriptome analysis at the early nodulation stage showed an induction of putative defense response genes at $1 \mathrm{~h}$ after inoculation with rhizobia (Lohar et al. 2006). Either NO, ROS, or both may trigger plant defense responses against symbiotic rhizobia; that is, like pathogenic microorganisms, symbiotic rhizobia also appear to induce genes involved in the defense system of host plants. Thus, to establish a successful symbiosis, rhizobia must cancel or avoid the host defense responses (Mithöfer 2002).

Class $1 \mathrm{Hb}$ affect various physiological processes through their association with NO. For instance, Mhb1, a class $1 \mathrm{Hb}$ of Medicago sativa, interferes with NO functions during pathogenic responses. Overexpression of $M h b l$ in tobacco plants resulted in fewer lesions in leaves when they were challenged with incompatible bacteria or tobacco necrosis virus, as compared with control plants (Seregélyes et al. 2003). Thus, in this study we focused on NO production and the expression of plant class $1 \mathrm{Hb}$ genes as indicators of plant responses against various bacteria in the rhizosphere.

We reported previously that NO was produced rapidly in $L$. japonicus by inoculation with $M$. loti MAFF303099 (Shimoda et al. 2005). In the present study, NO was specifically and transiently induced by symbiotic $M$. loti. Considering the function of NO in the plant defense system, initially L. japonicus roots seem to recognize $M$. loti as a biotic stress or a pathogen attack rather than as a symbiont. Lohar and associates (2006) also reported a strong suppression of putative defense response genes in Medicago truncatula after inoculation with symbiotic rhizobia, particularly at $48 \mathrm{~h}$. This suggests that the defense response of the host plant is aborted through an unknown mechanism.

It has been reported that $\mathrm{LjHbl}$ is induced by $\mathrm{NO}$ and that c-PTIO represses the induction, suggesting that NO is an actual inducer of $\mathrm{LjHbl}$ in L. japonicus (Shimoda et al. 2005). When a host legume interacts with its symbiotic rhizobia, NO was produced accompanied by the expression of a class $1 \mathrm{Hb}$ gene (Figs. 3 and 5). We propose that NO in roots is produced initially as a defense against the inoculation of symbiotic rhizobia and that class $1 \mathrm{Hb}$ then modulates the NO levels. Furthermore, class $1 \mathrm{Hb}$ serves as a NO scavenger only in the roots at the site of inoculation with symbiotic rhizobia. It is unclear whether the transient NO production is essential for initiation of the symbiosis; however, once NO is produced by the host plant, it is essential to reduce the NO level in order for the symbiotic rhizobia to colonize on the root. Because NO itself functions as an inducer of class $1 \mathrm{Hb}$ genes (Shimoda et al. 2005), the transient expression of these genes may be induced by NO. When the NO level is low enough to be fully removed by class $1 \mathrm{Hb}$, the defense response of the host plant will be cancelled. Another possibility is that the symbiotic rhizobia actively induce class $1 \mathrm{Hb}$ genes to reduce the level of NO. If class $1 \mathrm{Hb}$ serves as a NO scavenger in the roots, it might be involved in the first step of symbiosis. We cannot elucidate why nonsymbiotic rhizobia do not induce the production of NO and the gene expression of class $1 \mathrm{Hb}$. Further research is needed to clarify whether rhizobia possess some factor (e.g., Nod factor) that induces class $1 \mathrm{Hb}$ genes as well as to identify the rhizobial components that induce NO production.

In the interaction between $L$. japonicus and the plant pathogens we used in the present study, NO was produced continuously without expression of the class $1 \mathrm{Hb}$ gene $L j H b 1$, despite the fact that NO itself is an inducer of $\mathrm{LjHbl}$. Some but not all plant pathogens, at least the plant pathogens used in the present study, may be able to repress the expression of class $1 \mathrm{Hb}$ and induce high levels of NO. Although we need further testing, it might be one of the common characteristics of plant pathogens. High NO levels can either be protective, by activating defense responses and suppressing the growth of pathogenic bacteria, or toxic for the plant cells (Beligni and Lamattina 1999). However, continuous production of NO by inoculation with a plant pathogen may cause damage to roots of $L$. japonicus, thus promoting the growth of pathogenic bacteria.

The infiltration of $P$. syringae pv. glycinea MAFF302690 in the leaves did not induce any obvious symptoms in L. japonicus, although inoculation of the roots with this strain induced continuous NO production. This suggests that L. japonicus recognizes $P$. syringae pv. glycinea MAFF302690 as a putative pathogen. In contrast, $P$. syringae pv. pisi MAFF730032 induced hypersensitive reaction-like symptoms in the leaves. Tada and associates (2004) reported that alteration of the ratio of NO and ROS may induce a variant set of defense responses. The NO/ROS ratio may be different between $P$. syringae pvs. glycinea and pisi, such that the hypersensitive reaction-like symptoms will be induced only by the latter. Infiltration by $P$. syringae pv. glycinea into other ecotypes and $L$. japonicus mutants such as harl, which is hyperinfected by mycorrhizal fungi and root-parasitic nematodes, will provide clues to under-

Table 1. Bacterial strains

\begin{tabular}{|c|c|c|c|}
\hline \multirow[b]{2}{*}{ Bacterial strain } & \multirow[b]{2}{*}{ Host plant (isolation source) } & \multicolumn{2}{|c|}{ Response of Lotus japonicus } \\
\hline & & Inoculation to roots & Infiltration to leaves \\
\hline Mesorhizobium loti MAFF303099 & L. japonicus (root nodule) & Formation of nitrogen-fixing nodules & No symptom \\
\hline Sinorhizobium meliloti 1021 & Medicago sativa (root nodule) & No change & N.t. ${ }^{a}$ \\
\hline Bradyrhizobium japonicum USDA110 & Glycine $\max$ (root nodule) & No change & N.t. \\
\hline Ralstonia solanacearum MAFF730135 & Solanum tuberosum (stem) & $\begin{array}{l}\text { Etiolation of leaves, brownish pigmentation } \\
\text { of root tip, inhibition of plant growth }\end{array}$ & $\begin{array}{l}\text { Withering and death of } \\
\text { the infiltrated leaf }\end{array}$ \\
\hline Pseudomonas syringae pv. pisi MAFF730032 & Pisum sativum (stem) & $\begin{array}{l}\text { Brownish pigmentation of root tip, } \\
\text { inhibition of primary root elongation }\end{array}$ & $\begin{array}{l}\text { Withering and death of the } \\
\text { infiltrated leaf }^{c}\end{array}$ \\
\hline P. syringae pv. glycinea MAFF302690 & Glycine $\max$ (leaf) & Brownish pigmentation of root tip & No symptom ${ }^{\mathrm{c}}$ \\
\hline
\end{tabular}

\footnotetext{
${ }^{\mathrm{a}}$ N.t. $=$ not tested.

${ }^{\mathrm{b}}$ Kaku et al., unpublished data.

c Nakagawa et al., unpublished data.
} 
standing the different responses of L. japonicus against the two P. syringae pathovars.

In plant-microbe interactions, the function of $\mathrm{NO}$ and class $1 \mathrm{Hb}$ is not completely understood. Recently, Baudouin associates (2006) and Pii and associates (2007) reported NO in the root nodules of Medicago truncatula and Medicago sativa, and we detected enhanced expression of class $1 \mathrm{Hb}$ genes in the root nodules of Medicago sativa (data not shown) and L. japonicus (Uchiumi et al. 2002). Sasakura and associates (2006) suggested that class $1 \mathrm{Hb}$ contributes to the symbiotic nitrogen fixation between Frankia spp. and the actinorhizal plant Alnus firma. Based on the present study, class $1 \mathrm{Hb}$ appears to be involved in controlling the plant defense response during the initial stage of plant-microbe interactions. The modulation of NO by class $1 \mathrm{Hb}$ may be one of the critical steps for successful symbiotic nitrogen fixation.

\section{MATERIALS AND METHODS}

\section{Plant materials and bacterial strains.}

L. japonicus MG-20 Miyakojima (Kawaguchi 2000) was used throughout the experiments. M. loti MAFF303099 (Kaneko et al. 2000) was used as a symbiotic partner of $L$. japonicus. S. meliloti 1021 (Meade et al. 1982) and B. japonicum USDA110 (Johnson and Means 1964) were used as nonsymbiotic partners of $L$. japonicus. $R$. solanacearum MAFF730135 (isolated from potato stem), P. syringae pv. pisi MAFF730032 (isolated from Pisum sativum stem), and P. syringae pv. glycinea MAFF302690 (isolated from G. max leaves) were used as plant pathogens. The relevant characteristics of bacterial strains are listed in Table 1 .

\section{Inoculation of bacteria to plants.}

L. japonicus seeds were scarified with sulfuric acid for $10 \mathrm{~min}$ and were then rinsed with sterilized distilled water. Seeds were surface-sterilized with a $2 \%$ sodium hypochlorite solution containing $0.02 \%$ Tween 20 and were germinated on agar plates at $25^{\circ} \mathrm{C}$ in the dark. After 3 days, the seedlings were transferred to $1.5 \%$ Fåhraeus agar plates (Fåhraeus 1957) and were grown under a 16 -h-light and 8 -h-dark cycle at $25^{\circ} \mathrm{C}$ for 10 days.

Rhizobia were grown at $28^{\circ} \mathrm{C}$ to the stationary phase in yeast-mannitol liquid medium (Keele et al. 1969). $R$. solanacearum MAFF730135 was grown at $28^{\circ} \mathrm{C}$ to the stationary phase in peptone-sucrose liquid medium (Tsuchiya et al. 1982). P. syringae pvs. pisi MAFF730032 and glycinea MAFF302690 were grown at $28^{\circ} \mathrm{C}$ to the stationary phase in Luria-Bertani medium containing $10 \mathrm{mM} \mathrm{MgCl} 2$. Each bacterial culture was centrifuged and washed with sterilized distilled water; bacterial cells were then suspended in sterilized water at a concentration of $1 \times 10^{7}$ cells per milliliter. The bacterial suspension was directly applied to the roots of 14-dayold plants growing on plates or infiltrated into the leaves using a disposable syringe.

\section{Isolation of total RNA from $L$. japonicus.}

Whole plants or tissues were quickly frozen in liquid nitrogen and were stored at $-80^{\circ} \mathrm{C}$ until further use. Total RNA was prepared using the Plant Total RNA Extraction miniprep system (Viogene, Sunnyvale, CA, U.S.A.). DNase treatment was performed using deoxyribonuclease RT-Grade (Wako, Osaka, Japan). RNA was then precipitated by ethanol in the presence of ethachinmate (Wako) as a carrier and was resuspended in RNase-free water.

\section{Analysis of expression of $\mathbf{H b}$ genes by real-time RT-PCR.}

To quantify the relative amount of transcripts derived from each $\mathrm{Hb}$ gene, real-time RT-PCR was performed in a $25-\mu \mathrm{l}$ reaction mixture containing $12.5 \mu \mathrm{l}$ of SYBR Green PCR master mix (Applied Biosystems, Foster City, CA, U.S.A.), $100 \mathrm{ng}$ of total RNA, $10 \mathrm{U}$ of RNase inhibitor, $12.5 \mathrm{U}$ of Superscript II-RT (Invitrogen Japan, Tokyo), and $0.2 \mu \mathrm{M}$ of each primer. The enzymatic reactions were performed with a 7300 RealTime PCR system (Applied Biosystems). A reverse transcription reaction was performed at $48^{\circ} \mathrm{C}$ for $30 \mathrm{~min}$, followed by heating at $95^{\circ} \mathrm{C}$ for $10 \mathrm{~min}$. Target genes were then amplified by 40 cycles of $95^{\circ} \mathrm{C}$ for $15 \mathrm{~s}$ and $60^{\circ} \mathrm{C}$ for $1 \mathrm{~min}$. Sequences of primers for real-time RT-PCR were as follows (forward and reverse): 5'-CCTTTGGAGGAGAACCCCAA-3' and 5'-GAG CTGCTGATTCACAAGTCATG-3' for $\mathrm{LjHbl;}$ 5' $^{\prime}$-TCTGGRC CYAMGCAYAGTC-3' and 5'-CRTCRCGWGTCAGTSCAAA A-3' for $L j L b$; and $5^{\prime}$-AGAGGGTTTAAAGATCAAAT-3' and 5'-ATGTCAATTCATCACGTTTT-3' for initiation factor 4A3 gene $(L j e I F-4 A)$. Primers were designed with the Primer Express software (Applied Biosystems). LjeIF-4A of L. japonicus was used for normalization of the results of real-time RT-PCR.

Detection of NO production by fluorescence microscopy.

A stock solution of DAF-FM DA (5 mM in dimethylsulfoxide) was diluted 500-fold in water before use. Throughout the experiments, 14-day-old plants were used. Plants that generated strong autofluorescence were not used for further experiments. The plants inoculated with $M$. loti MAFF303099, $R$. solanacearum MAFF730135, P. syringae pv. pisi MAFF730032, or $P$. syringae pv. glycinea MAFF302690 were divided into four groups. The plants in one of the four groups were observed immediately $(0 \mathrm{~h})$ and those in the other three groups were incubated for 4,10 , or $24 \mathrm{~h}$. After incubation, the plants to be observed were placed for $30 \mathrm{~min}$ on filter paper soaked with the DAF-FM DA solution, and the fluorescence images of the roots were then observed under a microscope. Images were captured by a Leica DMLB microscope equipped with a Leica DC2000 digital camera (Leica Microsystems, Wetzlar, Germany). For detection of DAF-FM fluorescence, filter sets of 470 (excitation) and $525 \mathrm{~nm}$ (emission) were used.

\section{Quantitation of NO by fluorescence spectrophotometer.}

A stock solution of DAF-FM (7 mM in dimethylsulfoxide) was diluted 1,000-fold in water before use. Roots of L. japonicus (14 days after germination) were inoculated with $M$. loti MAFF303099, $R$. solanacearum MAFF730135, $P$. syringae pv. pisi MAFF730032, or $P$. syringae pv. glycinea MAFF302690 and were incubated for $3.5 \mathrm{~h}$. Roots were cut off and soaked in DAF-FM solution for $30 \mathrm{~min}$. The RFU of the DAF-FM solution were measured using a NanoDrop ND3300 fluorospectrometer (NanoDrop Technologies, Inc., Wilmington, DE, U.S.A.). Wavelengths for excitation and emission were 470 and $515 \mathrm{~nm}$, respectively.

\section{ACKNOWLEDGMENTS}

We thank H. Kaku and H. Ochiai (National Institute of Agribiological Sciences, Tsukuba, Japan) for information about $R$. solanacearum and $\mathrm{T}$. Nakagawa and K. Takeuchi (National Institute of Agribiological Sciences) for information about $P$. syringae strains. T. Nakagawa also instructed us in filtration technique. We also thank Y. Hikichi (Kouchi University) and $\mathrm{K}$. Toyoda (Okayama University) for their valuable comments and suggestions on the manuscript.

\section{LITERATURE CITED}

Appleby, C. A. 1992. The origin and functions of haemoglobin in plants Sci. Prog. 76:365-398.

Arredondo-Peter, R., Hargrove, M. S., Moran, J. F., Sarath, Moran, J. F., Lohrman, J., Olson, J. S., and Klucas, R. V. 1997. Rice hemoglobin. Plant Physiol. 115:1259-1266.

Arredondo-Peter, R., Hargrove, M. S., Moran, J. F., Sarath, G., and Klucas, 
R. V. 1998. Plant hemoglobins. Plant Physiol. 118:1121-1125.

Baron, C., and Zambryski, P. C. 1995. The plant response in pathogenesis, symbiosis, and wounding: Variations on a common theme? Annu. Rev. Genetics 29:107-129.

Baudouin, E., Pieuchot, L., Engler, G., Pauly, N., and Puppo, A. 2006. Nitric oxide is formed in Medicago truncatula-Sinorhizobium meliloti functional nodules. Mol. Plant-Microbe Interact. 19:970-975.

Beligni, M. V., and Lamattina, L. 1999. Is nitric oxide toxic or protective? Trends Plant Sci. 4:229-300.

Beligni, M. V., and Lamattina, L. 2000. Nitric oxide stimulates seed germination and de-etiolation, and inhibits hypocotyl elongation, three light-inducible responses in plants. Planta 210:215-221.

Delledonne, M. 2005. NO news is good news for plants. Curr. Opin. Plant Biol. 8:1-7.

Desikan, R., Cheung, M. K., Bright, J., Henson, D., Hancock, J. T., and Neill, S. J. 2004. ABA, hydrogen peroxide and nitric oxide signaling in stomatal guard cells. J. Exp. Bot. 55:205-212.

Dordas, C., Rivoal, J., and Hill, R. D. 2003a. Plant haemoglobins, nitric oxide and hypoxic stress. Ann. Bot. 91:173-179.

Dordas, C., Hasinoff, B. B., Igamberdiev, A. U., Manac'h, N., Rivoal, J., and Hill, R. D. 2003b. Expression of a stress-induced hemoglobin affects NO levels produced by alfalfa root cultures under hypoxic stress. Plant J. 35:763-770.

Dordas, C., Hasinoff, B. B., Rivoal, J., and Hill, R. D. 2004. Class-1 hemoglobins, nitrate and NO levels in anoxic maize cell-suspension cultures. Planta 219:66-72.

Durner, J., Wendehenne, D., and Klessing, D. 1998. Defense gene induction in tobacco by nitric oxide, cyclic GMP, and cyclic ADP-ribose. Proc. Natl. Acad. Sci. U.S.A. 95:10328-10333.

Estabrook, E. M., and Sengupta-Gopalan, C. 1991. Differential expression of phenylalanine ammonia-lyase and chalcone synthase during soybean nodule development. Plant Cell 3:299-308.

Fåhraeus, G. M. 1957. The infection of clover root hair by nodule bacteria studied by a single glass slide technique. J. Gen. Microbiol. 16:374381.

Hancock, J. T., Desikan, R., Clarke, A., Hurst, R. D., and Neill, A. J. 2002. Cell signaling following plant/pathogen interactions involves the generation of reactive oxygen and reactive nitrogen species. Plant Physiol. Biochem. 40:611-617.

Hill, R. D. 1998. What are hemoglobins doing in plants? Can. J. Bot 76:707-712.

Hunt, P. W., Watts, R. A., Trevaskis, B., Llewelyn, D. J., Burnell, J., Dennis, E. S., and Peacock, W. J. 2001. Expression and evolution of functionally distinct haemoglobin genes in plants. Plant Mol. Biol. 47:677-692.

Hunt, P. W., Klok, E. J., Trevaskis, B., Watts, R. A., Ellis, M. H., Peacock, W. J., and Dennis, E. S. 2002. Increased level of hemoglobin 1 enhances survival of hypoxic stress and promotes early growth in Arabidopsis thaliana. Proc. Natl. Acad. Sci. U.S.A. 99:17197-17202.

Johnson, H. W., and Means, U. M. 1964. Selection of competitive strains of soybean nodulating bacteria. Agron. J. 56:60-62.

Kaneko, T., Nakamura, Y., Sato, S., Asamizu, E., Kato, T., Sasamoto, S., Watanabe, A., Idesawa, K., Ishikawa, A., Kawashima, K., Kimura, T., Kishida, Y., Kiyokawa, S., Kohara, M., Matsumoto, M., Matsuno, A., Mochizuki, Y., Nakayama, S., Nakazaki, N., Shimpo, S., Sugimoto, M., Takeuchi, C., Yamada, M., and Tabata, S. 2000. Complete genome structure of the nitrogen-fixing symbiotic bacterium Mesorhizobium loti. DNA Res. 7:331-338.

Katagiri, F., Thilmony, R., and He, S. Y. 2002. The Arabidopsis thaliana-Pseudomonas syringe interaction. Pages 1-35 in: The Arabidopsis Book. C. R. Somerville and E. M. Meyerowitz, eds. The American Society of Plant Biologists, Rockville, MD, U.S.A. Published online.

Kawaguchi, M. 2000. Lotus japonicus 'Miyakojima' MG-20: An earlyflowering accession suitable for indoor handing. J. Plant Res. 113:507509

Keele, B. B., Hamilton, P. B., Jr., and Elkan, G. H. 1969. Glucose catabolism in Rhizobium japonicum. J. Bacteriol. 97:1184-1191.

Kubo, H. 1939. Über hämoprotein aus den wurzelknöllchen von leguminosen. Acta Phytochemica (Tokyo) 11:195-200.

Lawson, C. G. R., Djordjevic, M. A., Weinman, J. J., and Rolfe, B. G. 1994. Rhizobium inoculation and physical wounding result in the rapid induction of the same chalcone synthase copy in Trifolium subterraneum. Mol. Plant-Microbe Interact. 7:498-507.

Lohar, D. P., Sharopova, N., Endre, G., Peñuela, S., Samac, D., Town, C., Silverstein, K. A. T., and VandenBosch, K. A. 2006. Transcript analysis of early nodulation events in Medicago truncatula. Plant Physiol. 140:221-234.

Meade, H. M., Long, S. R., Ruvkun, G. B., Brown, S. E., and Ausubel, F. M. 1982. Physical and genetic characterization of symbiotic and auxotrophic mutants of Rhizobium meliloti induced by transposon Tn5 mutagenesis. J. Bacteriol. 149:114-122.

Mishina, T. E., and Zeier, J. 2007. Pathogen-associated molecular pattern recognition rather than development of tissue necrosis contributes to bacterial induction of systemic acquired resistance in Arabidopsis. Plant J. 50:500-513.

Mithöfer, A. 2002. Suppression of defence in rhizobia-legume symbiosis. Trends Plant Sci. 7:440-444.

Neill, S. J., Desikan, R., and Hancock, J. T. 2003. Nitric oxide signaling in plants. New Phytol. 159:11-35.

Nomura, K., Melotto, M., and He, S. Y. 2005. Suppression of host defense in compatible plant-Pseudomonas syringae interactions. Curr. Opin. Plant Biol. 8:361-368.

Perazzolli, M., Dominici, P., Romero-Puertas, M. C., Zago, E., Zeier, J., Sonoda, M., Lamb, C., and Delledonne, M. 2004. Arabidopsis nonsymbiotic hemoglobin AHb1 modulates nitric oxide bioactivity. Plant Cell 16:2785-2794.

Pii, Y., Crimi, M., Cremonese, G., Spena, A., and Pandolfini, T. 2007. Auxin and nitric oxide control indeterminate nodule formation. BMC Plant Biol. 7:21. Published online

Polverari, A., Molesini, B., Pezzotti, M., Buonaurio, R., Marte, M., and Delledonne, M. 2003. Nitric oxide-mediated transcriptional changes in Arabidopsis thaliana. Mol. Plant-Microbe Interact. 16:1094-1105.

Qu, Z. L., Zhong, N. Q., Wang, H. Y., Chen, A. P., Jian, G. L., and Xia, G. X. 2006. Ectopic expression of the cotton non-symbiotic hemoglobin gene $\mathrm{GhHbl}$ triggers defense responses and increases disease tolerance in Arabidopsis. Plant Cell Physiol. 47:1058-1068.

Romero-Puertas, M. C., Perazzolli, M., Zago, E. D., and Delledonne, M. 2004. Nitric oxide signaling functions in plant-pathogen interactions. Cell. Microbiol. 6:795-803.

Santos, R., Hérouart, D., Sigaud, S., Touati, D., and Puppo, A. 2001. Oxidative burst in Alfalfa-Sinorhizobium meliloti symbiotic interaction. Mol. Plant-Microbe Interact. 14:86-89.

Sasakura, F., Uchiumi, T., Shimoda, Y., Suzuki, A., Takenouchi, K., Higashi, S., and Abe, M. 2006. A class 1 hemoglobin gene from Alnus firma functions in symbiotic and nonsymbiotic tissues to detoxify nitric oxide. Mol. Plant-Microbe Interact. 19:441-450.

Seregélyes, C., Barna, B., Hennig, J., Konopka, D., Pasternak, T. P., Luács, N., Fehér, A., Horváth, G. V., and Dudits, D. 2003. Phytoglobins can interfere with nitric oxide functions during plant growth and pathogenic responses: A transgenic approach. Plant Sci. 165:541-550.

Seregélyes, C., Igamberdiev, A. U., Maassen, A., Hennig, J., Dudits, D. and Hill, R. D. 2004. NO-degradation by alfalfa class 1 hemoglobin (Mhb1): A possible link to $P R-1 a$ gene expression in Mhb1overproducing tobacco plants. FEBS (Fed. Eur. Biochem. Soc.) Lett. 571:61-66.

Shimoda, Y., Nagata, M., Suzuki, A., Abe, M., Sato, S., Kato, T., Tabata, S., Higashi, S., and Uchiumi, T. 2005. Symbiotic rhizobium and nitric oxide induce gene expression of non-symbiotic hemoglobin in Lotus japonicus. Plant Cell Physiol. 46:99-107.

Tada, Y., Mori, T., Shinogi, T., Yao, N., Takahashi, S., Betsuyaku, S., Sakamoto, M., Park, P., Nakayashiki, H., Tosa, Y., and Mayama, S. 2004. Nitric oxide and reactive oxygen species do not elicit hypersensitive cell death but induce apoptosis in the adjacent cells during the defense response of Oat. Mol. Plant-Microbe Interact. 17:245-253.

Trevaskis, B., Watts, R. A., Andersson, C. R., Llewellyn, D. J., Hargrove, M. S., Olson, J. S., Dennis, E. S., and Peacock, W. J. 1997. Two hemoglobin genes in Arabidopsis thaliana: The evolutionary origins of leghemoglobins. Proc. Natl. Acad. Sci. U.S.A. 94:12230-12234.

Tsuchiya, K., Mew, T. W., Wakimoto, S. 1982. Bacteriological and pathological characteristics of wild types and induced mutants of Xanthomonas campestris pv. oryzae. Phytopathology 72:43-46.

Uchiumi, T., Shimoda, Y., Tsuruta, T., Mukoyoshi, Y., Suzuki, A., Senoo, K., Sato, S., Kato, T., Tabata, S., Higashi, S., and Abe, M. 2002. Expression of symbiotic nonsymbiotic globin genes responding to microsymbionts on Lotus japonicus. Plant Cell Physiol. 43:1351-1358.

Vailleau, F., Sartorel, E., Jardinaud, M.-F., Chardon, F., Genin, S., Huguet, T., Gentzbittel, L., and Petitprez, M. 2007. Characterization of the interaction between the bacterial wilt pathogen Ralstonia solanacearum and the model legume plant Medicago truncatula. Mol. Plant-Microbe Interact. 20:159-167.

Wang, R., Guegler, K., LaBrie, S. T., and Crawford, N. M. 2000. Genomic analysis of a nutrient response in Arabidopsis reveals diverse expression patterns and novel metabolic and potential regulatory genes induced by nitrate. Plant Cell 12:1491-1509.

Zabala, G., Zou, J., Tuteja, J., Gonzalez, D. O., Clough, S. J., and Vodkin, L. O. 2006. Transcriptome changes in the phenylpropanoid pathway of Glycine max in response to Pseudomonas syringae infection. BMC Plant Biol. 6:26. Published online. 